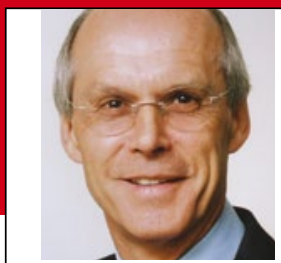

Prof. Dr. med. H. S. FüeßI

Isar-AmperKlinikum, KI. München-Ost, Haar

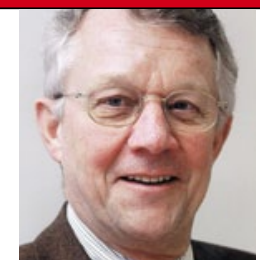

Prof. Dr. med. H. Holzgreve

Internist, Kardiologische Praxis, München

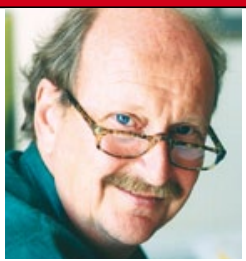

Prof. Dr. med.

\section{E. Ernst}

Peninsular

Medical School,

University

of Exeter/UK

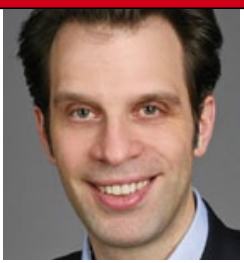

Dr. med. Markus Busch

Robert KochInstitut Berlin

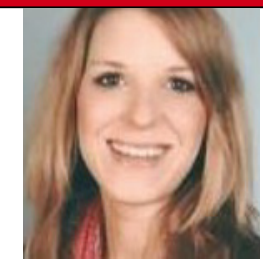

Dipl.-Psych. Valeska Pape

Klinik für Psychiatrie und Psychotherapie der Univ. Mainz

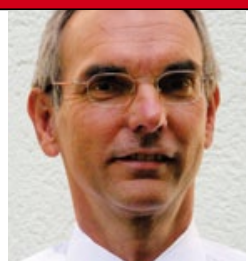

Prof. Dr. med. A. Gillissen

Klinik für Lungen und Bronchialmedizin, Kassel

\title{
Atherosklerose auf dem Rückzug
}

\section{Die gefallenen Soldaten der US-ame- rikanischen Kriege in Korea, Vietnam und im Irak erweisen der Wissen- schaft einen letzten Dienst.}

- Die Sterblichkeit an der koronaren Herzerkrankung erreichte in den USA 1968 ihren Höhepunkt und ist seitdem um $72 \%$ zurückgegangen. Obwohl die Medizin einen Großteil dieses Erfolgs für sich in Anspruch nimmt, spielt wahrscheinlich die Modifikation von Risikofaktoren eine größere Rolle.

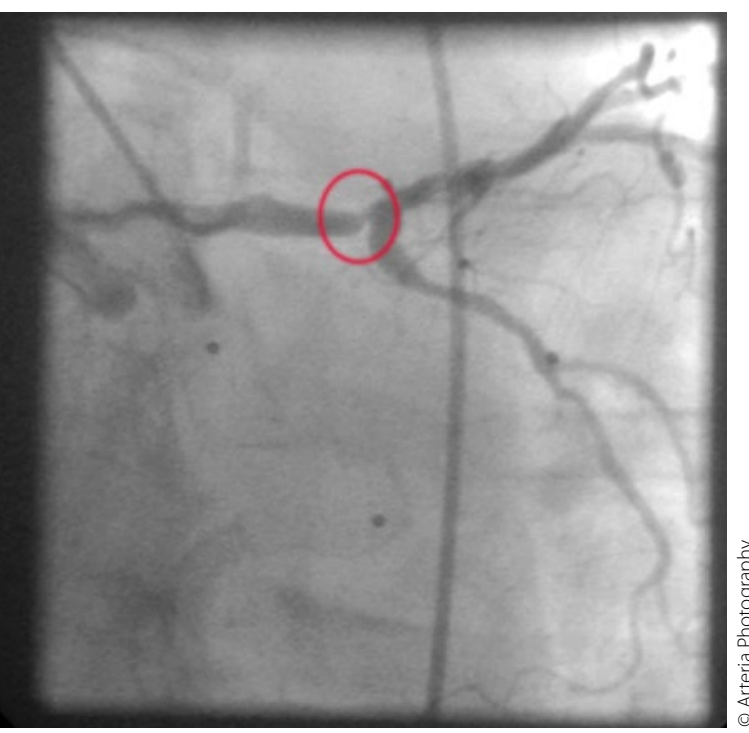

Risikofaktoren meiden zahlt sich aus: Koronarsklerose heute erheblich seltener.
Die wissenschaftliche Analyse des Verlaufs der koronaren Herzkrankheit erlebte 1953 einen ersten Höhepunkt durch die systematische Obduktion von im Koreakrieg gefallenen Soldaten. Pathologen der US-Streitkräfte stellten eine 77\%-ige Prävalenz der Koronarsklerose bereits bei jungen asymptomatischen Soldaten fest. Nun liegen entsprechende Obduktionsergebnisse auch von Soldaten vor, die zwischen Oktober 2001 und August 2011 beim Einsatz im Irak ums Leben kamen.

Die Prävalenz der koronaren Atherosklerose in jeder Form betrug bei den 3832 obduzierten Soldaten 8,5\%. Eine schwere Koronarsklerose lag in 2,3\%, eine mittelgradige in $4,7 \%$ und eine minimale in 1,5\% vor. Erwartungsgemäß waren Soldaten mit Atherosklerose signifikant älter (30,5 $\pm 8,1$ Jahre $)$ als solche ohne diese Veränderungen $(25,3 \pm 5,6$ Jahre). Soldaten mit Atherosklerose wiesen zu 50\% eine Dyslipidämie auf, 44\% hatten eine Hypertonie und 22,3\% waren adipös. Die altersadjustierten Prävalenzquotienten für die Diagnosen Dyslipidämie, Hypertonie und Adipositas betrugen 2,09, 1,88 und 1,47.

Erstaunlicherweise war das Rauchen nicht mit einer signifikant erhöhten Prävalenz der Atheromatose assoziiert. Allerdings ging die Zahl der Raucher in den letzten 40 Jahren deutlich zurück, ein Trend, der durch die amerikanische Armee auch stark gefördert wird.

\section{- B. J. Weber et al. \\ (Korres.: bryant.weber@usuhs.edu): Prevalence of and risk factors for autopsy-determined atherosclerosis among US Service Members, 2001-2011. JAMA 2012; 308: 2577-2583}

\section{Kommentar}

Mit einer Prävalenz von nur 8,5\% ist die Atherosklerose im Vergleich zur Rate bei Gefallenen des Koreakriegs mit 77\% und des Vietnamkriegs mit 45\% drastisch zurückgegangen. Die Studie ist indirekt ein Beleg dafür, dass der Rückgang der Koronartoten nur zum geringeren Teil auf den medizinischen Fortschritt und zum größeren Teil auf eine Risikofaktorprophylaxe zurückzuführen ist. Schließlich handelte es sich in allen drei Kriegen fast durchweg um junge Männer, bei denen die Grundlage der Koronarsklerose bereits gelegt war, lange ehe es zu klinischen Symptomen und einer manifesten koronaren Herzerkrankung kam. Mit der Zunahme der Adipositas und des Diabetes mellitus könnte es sein, dass dieser Trend bereits gestoppt ist oder sich sogar umgekehrt hat. Wir wünschen uns allerdings, dass es nicht eines weiteren Krieges bedarf, um auch das wissenschaftlich festzustellen. 